\title{
Introduction: Pseudomonas aeruginosa
}

\author{
NICHOLAS M MOORE, MARIBETH L FLAWS
}

\author{
ABBREVIATIONS: RNA = ribonucleic acid; rRNA = \\ ribosomal ribonucleic acid
}

INDEX TERMS: Pseudomonas aeruginosa, molecular based methods, anti-microbial resistance.

Clin Lab Sci 2011;24(1):41

Nicholas M. Moore, MS, MLS(ASCP), Rush University, Department of Medical Laboratory Science, Chicago, IL

Maribeth L. Flaws, PhD, SM(ASCP)SI, Rush University, Department of Medical Laboratory Science, Chicago, IL

Address for Correspondence: Nicholas M. Moore, MS, MLS (ASCP), Department of Medical Laboratory Science, 600 S. Paulina St., Suite 1014, Chicago, IL 60612, 312942-2111, Fax: (312) 942-6464, Nicholas_Moore@ rush.edu

In 1882, Carle Gessard (1850-1925) first isolated Pseudomonas aeruginosa ${ }^{1}$ from wound infections of soldiers whose bandages had a blue and green color. Walter Migula (1863-1938) first proposed the genus Pseudomonas in 1894 to encompass all gram-negative, rod-shaped aerobic bacilli that had polar flagella. Because this definition was so broad, unrelated organisms were added to the genus to the point that in 1984, there were over 100 species of Pseudomonas listed in Bergey's Manual of Systematic Bacteriology. ${ }^{2,3}$ When molecular-based methods were developed that involved sequencing and comparing $16 \mathrm{~S}$ ribosomal RNA from all of these organisms, scientists were able to reassign many organisms originally classified as Pseudomonas into other genera. First, rRNA-DNA hybridization studies described by Palleroni ${ }^{4}$ divided the genus into five groups called rRNA Groups I-V. Over the last 30 years, members of rRNA Groups II-V have been all moved to different genera such as Burkholderia, Ralstonia,
Acidovorax, and Brevundimonas. ${ }^{3}$ The only remaining species of Pseudomonas are members of rRNA Group I and are divided into the following eight groups: $P$. aeruginosa, $P$. chlororaphis, $P$. fluorescens, $P$. pertucinogena, $P$. putida, $P$. stutzeri, $P$. syringae and incertae sedis, which is Latin for uncertain placement.

$P$. aeruginosa is a common organism in the soil and in water and it can also be found on plants and animals. It is an aerobic, saccharolytic, non-spore forming gramnegative bacillus measuring 0.5 to $0.8 \mu \mathrm{m}$ by 1.5 to 3.0 $\mu \mathrm{m} .{ }^{5}$ Most strains of $P$. aeruginosa possess a single polar flagellum that is used for motility. Pseudomonas aeruginosa commonly produces two soluble pigments: pyocyanin, which gives colonies a blue color and pyoverdin, also known as the fluorescent pigment, which is a yellow-green or yellow-brown pigment. When a strain of $P$. aeruginosa produces both pyoverdin and pyocyanin, the resulting colonies have a blue-green color. This organism may also produce other watersoluble pigments such as pyorubrin or pyomelanin which give colonies a red or brown color, respectively. On sheep blood agar plates, colonies of $P$. aeruginosa often display beta-hemolysis and a greenish metallic sheen due to their pigment production. No other species of gram-negative nonfermenters produce pyocyanin, making its presence helpful in identifying the organism. One of the most recognizable signs of an unknown colony being $P$. aeruginosa is the characteristic fruity, grape-like odor from the production of 2-aminoacetophenone by the organism.

$P$. aeruginosa is a glucose and lactose non-fermenting bacterium that is frequently isolated from hospitalized patients. The organism is an obligate aerobe, although it can use nitrate and arginine as a final electron acceptor when $\mathrm{O}_{2}$ is not available allowing the organism to grow anaerobically. ${ }^{5}$ It tests positive with $\mathrm{N}, \mathrm{N}, \mathrm{N}^{\prime}, \mathrm{N}^{\prime}$ tetramethyl- $p$-phenylenediamine dihydrochloride (oxidase). Because of its relatively simple nutritional 


\section{FOCUS: PSEUDOMONAS AERUGINOSA}

requirements for growth, $P$. aeruginosa has been isolated from many different environments, including even distilled water. It is very hardy and can grow in temperatures ranging from $37-42^{\circ} \mathrm{C}$.

Isolates of $P$. aeruginosa can have multiple different colony morphologies. Most colonies are flat and spread out over the agar surface. Depending on the pigment(s) produced, isolates will vary in color from the most common bluish-green to red or brown. P. aeruginosa isolated from patients with cystic fibrosis in particular will have a mucoid appearance due to the production of alginate. ${ }^{5}$ Alginate is a polysaccharide layer that surrounds and causes many individual bacterial cells to clump together into a biofilm making them harder to kill with antimicrobial agents. ${ }^{6}$

$P$. aeruginosa has been shown to cause a variety of diseases and thus has been isolated from almost any type of specimen. Infections can be acquired from the community or during a stay in a healthcare facility. Typical community-acquired infections include skin and soft tissue infections (e.g. hot tub folliculitis), keratitis linked to the use of contact lens, and otitis externa. Nosocomial infections are more likely to be invasive and include infections of the bloodstream, urinary tract, surgical sites, and the respiratory tract. Patients who are particularly susceptible to infection with $P$. aeruginosa are those who have burns, cystic fibrosis or are on a mechanical ventilator. Nosocomial infections caused by $P$. aeruginosa are very common; 11 $13.8 \%$ of all nosocomial infections are due to $P$. aeruginosa, with an even higher rate (13.2-22.6\%) of nosocomial infections among patients in an intensive care unit (ICU). ${ }^{7}$

Infections caused by $P$. aeruginosa have always been difficult to treat, but like other bacteria $P$. aeruginosa is becoming increasingly resistant to antimicrobial agents. ${ }^{8}$ To make matters worse, multidrug resistant $P$. aeruginosa has been identified where the organism is resistant to three or more antimicrobial agents and in one study accounted for almost $30 \%$ of all isolates obtained from patients in nursing homes and the ICU. ${ }^{8}$ Accurate methods for determining the susceptibility of $P$. aeruginosa to antimicrobial agents are needed now more than ever as is the need for tracking and documenting changes in the susceptibility pattern. Knowing the antibiogram of $P$. aeruginosa isolated in one facility is information that can be used to determine the most efficacious empirical therapy for patients suspected of having $P$. aeruginosa infections.

Because of the prevalence of infections caused by $P$. aeruginosa and the increasing incidence of drug resistance, this FOCUS series in Clinical Laboratory Science has been designed to provide an overview of the current body of knowledge of $P$. aeruginosa. It will cover three major topics: 1) epidemiology and pathogenesis; 2) resistance mechanisms; and 3) treatment options and strategies for patients with documented or suspected $P$. aeruginosa infections.

\section{REFERENCES}

1. Gessard C. Classics in infectious diseases. On the blue and green coloration that appears on bandages. By Carle Gessard (1850-1925). Rev Infect Dis 1984;6Suppl 3:S775-6.

2. Peix A, Ramirez-Bahena MH, Velazquez E. Historical evolution and current status of the taxonomy of genus Pseudomonas. Infection, Genetics \& Evolution 2009;9:113247.

3. Anzai Y, Kim H, Park J-Y, Wakabayashi H, Oyaizu H. Phylogenetic affiliation of the pseudomonads based on $16 \mathrm{~S}$ rRNA sequence. Int J Syst Evol Micro 2000;50:1563-89.

4. Palleroni NJ. Genus I. Pseudomonas Migula 1894. In Bergey's Manual of Systematic Bacteriology, vol 1, pp141-99, Krieg NR and Holt JG, editors. Baltimore, Williams and Wilkins.

5. Todar's Online Textbook of Bacteriology. Accessed online at <http://www.textbookofbacteriology.net/pseudomonas.html> on June 30, 2010.

6. Lambert PA. Mechanisms of antibiotic resistance in Pseudomonas aeruginosa. J R Soc Med. 2002; 95(41S): 22-6.

7. Driscoll JA, Brody SL, and Kollef MH. The epidemiology, pathogenesis and treatment of Pseudomonas aeruginosa infections. Drugs 2007;67:351-68.

8. Flamm RK, Weaver MK, Thornsberry C, et al. Factors associated with relative rates of antibiotic resistance in Pseudomonas aeruginosa isolates tested in clinical laboratories in the United States from 1999 to 2002. Antimicrob Agents Chemother 2004;48:2431-6. 